\title{
ERCC1 intron 1 was associated with breast cancer risk
}

Hosseini Mojgan ${ }^{1}$, Houshmand Massoud ${ }^{2,3}$, Ebrahimi Ahmad ${ }^{4}$

1Department of Science, Islamshahr Branch, Islamic Azad University, Tehran, Iran
2National Institute for Genetic Engineering and Biotechnology (NIGEB), Tehran, Iran
${ }^{3}$ Special Medical Center, Tehran, Iran
4Department of Molecular Genetics, Shiraz University of Medical Science, Shiraz, Iran

Submitted: 25 March 2011

Accepted: 18 September 2011

Arch Med Sci 2012; 8, 4: 655-658

DOI: 10.5114/aoms.2012.30289

Copyright (c) 2012 Termedia \& Banach

\author{
Corresponding author: \\ Mojgan Hosseini PhD \\ Department of Science \\ Islamshahr Branch \\ Islamic Azad University \\ Tehran, Iran \\ Phone/fax: +98-21-66936779 \\ E-mail: Mojgan- \\ Hosseini@iiau.ac.ir. \\ moj.hosseini@gmail.com
}

\begin{abstract}
Introduction: There are numerous studies addressing associations of polymorphisms in DNA repair genes and cancer risks because accurate and efficient DNA repair is crucial to genomic integrity and fidelity. ERCC1 is important in DNA nucleotide excision repair.

Material and methods: We genotyped constitutive variants of ERCC1 in approximately 300 adults with breast adenocarcinoma and 126 controls of Iranian women. In total, 426 Iranian sporadic breast cancer affected women compared to the control group were studied by PCR-RFLP for ERCC1 variant.

Results: The genotype ERCC1 TT has the highest frequency in both groups (36.6 in patients and 8.5 in controls). The genotype ERCC1 was the most important risk factor in our population [GG/AA odds ratio: $0.692,95 \%$ confidence interval (CI): 0.4-1.199, $p=0.188$; GG/AG odds ratio: $3.333,95 \% \mathrm{Cl}: 1.917-5.795, p=0.001$; AA/AG odds ratio: $0.208,95 \% \mathrm{Cl}: 0.124-0.348, p=0.342]$.
\end{abstract}

Conclusions: Our patients was associated with breast cancer risk.

Key words: ERCC1 gene, polymorphism, breast cancer, Mboll, polymerase chain reaction-restriction fragment length polymorphism, susceptibility factor.

\section{Introduction}

Breast cancer is the second most common cancer in the world and the most common cancer in Iranian women in rate [1, 2]. There are many studies on polymorphisms in DNA repair genes and cancer risks [1].

The DNA repair system is complex many of which are polymorphic [3] once of DNA repair genes, ERCC1 (ASE-1), whose products are important in nucleotide excision repair lie.

ASE-1 is positioned in an anti-sense orientation to and overlaps with the gene for ERCC1 and is possibly involved with the RNA polymerase I transcription complex.

Variation in efficiency of these processes might influence cancer development. Defective or inefficient repair could lead to accumulation of deleterious mutations in the absence of apoptotic destruction of DNA-damaged cells or cancer progression, by any of the previously mentioned mechanisms or by more efficient repair reducing effectiveness of chemotherapy aimed at DNA damage and resultant reduction of cancer cell killing.

We report here the allele frequencies of ERCC1 in breast cancer patients in Iran. 


\section{Material and methods}

\section{Patient data}

Analyses were conducted for 300 patients and 126 controls genotyped for ERCC1; ages were 35-55 years.

This study was ethically approved by the local Ethical Committee of Islamic Azad University from the point of view of patients' and also control group members' rights.

All patients in stage II (tumour 2-5 cm) participated in the Special Medical Centre, part of chemotherapy, Tehran, Iran. A questionnaire including questions on breast cancer risk factors was completed and each patient filled in a consent form. Blood samples were collected from patients and controls prior to the start of treatment.

Subjects were genotyped for ERCC1 using genomic DNA extracted from peripheral blood lymphocytes. DNA was isolated from peripheral blood using FelxiGene DNA extraction kit (Qiagen Germany).

\section{Genotyping}

The polymorphisms were detected using a modified polymerase chain reaction-restriction fragment length polymorphism (PCR-RFLP) method $[4,5]$. The

Table I. ERCC1 genotype frequencies [ $n(\%)]$ for cases and control: analyses of 300 affected women and 126 controls for ERCC1 genotype frequency shows that ERCC1 AA genotype has the highest frequency in both groups (36.5 in patient and 8.5 in control group). The $A A$ genotype is in the patient group 21.1 compared with controls 7.0. AG genotype is lower in the case group (12.7) compared to the control group (14.1)

\begin{tabular}{|cccc|}
\hline Genotype & $\begin{array}{c}\text { Patients } \\
n(\%)\end{array}$ & $\begin{array}{c}\text { Control } \\
n(\%)\end{array}$ & $\begin{array}{c}\text { Total } \\
n(\%)\end{array}$ \\
\hline$n$ & 300 & 126 & 426 \\
\hline ERCC1 & & & \\
\hline GG & $90(21.1 \%)$ & $30(7.0 \%)$ & $120(28.2 \%)$ \\
\hline AG & $54(12.7 \%)$ & $60(14.1 \%)$ & $114(26.8 \%)$ \\
\hline AA & $156(36.6 \%)$ & $36(8.5 \%)$ & $192(45.1 \%)$ \\
\hline
\end{tabular}

Table II. Comparison between genotypes, odds ratio and $p$ value showed that genotype ERCC1 $A A$ was the most important risk factor in our population; $A A$ odds ratio: $3.333,95 \% \mathrm{Cl}: 1.917-5.795, p=0.001 ; G G$ odds ratio: $0.692,95 \% \mathrm{Cl}: 0.4-1.199, p=0.188 ; A G$ odds ratio: $0.208,95 \% \mathrm{Cl}: 0.124-0.348, p=0.342$. After genotype ERCC1 AA, genotype GG was the most important risk factor in our population

\begin{tabular}{|lccc|}
\hline $\begin{array}{l}\text { Genotype } \\
\text { ERCC1 }\end{array}$ & Odds ratio & $\begin{array}{c}95 \% \text { confidence } \\
\text { interval }\end{array}$ & Value of $p$ \\
\hline$A G$ & 0.208 & $0.124-0.348$ & 0.342 \\
\hline$G G$ & 0.692 & $0.4-1.199$ & 0.188 \\
\hline$A A$ & 3.333 & $1.917-5.795$ & 0.001 \\
\hline
\end{tabular}

PCR primers were synthesized by TAG Copenhagen $A / S$. Primers were for each polymorphism as follows. ERCC1 intron 1 (ASE-1) (rs3212981) (255 bp) [6]. Forward: TAGTTCCTCAGTTTCCCG, Reverse: TGAGCCAATTCAGCCACT. The cycling conditions were $94^{\circ} \mathrm{C}, 30 \mathrm{~s} ; 55.5^{\circ} \mathrm{C}, 30 \mathrm{~s}$ ( 35 cycles); $72^{\circ} \mathrm{C}$, $60 \mathrm{~s}$. The PCR products were digested with 1 unit of Mboll, and separated on a $6 \%$ acrylamide gel.

This method is able to detect all three possible genotypes for the polymorphism: homozygous wild type, heterozygous variant type and homozygous variant type.

\section{Statistical analysis}

The genotypes and allelic frequencies of ERCC1 polymorphisms in patient and control groups were analysed by $\chi^{2}$ and Fisher's exact tests.

\section{Results}

Analyses of affected and controls show that genotype ERCC1 AA has the highest frequency in both groups (36.6 in patients and 8.5 in controls).

The frequency of genotype ERCC1 AG in patients was 12.7 compared with 14.1 in controls (Tables I-II, Figures 1-2).

The genotype ERCC1 was the most important risk factor in our population. Comparison between genotypes, odds ratio and $p$ value showed that the genotype ERCC1 GG/AG was the most important risk factor in our population: GG/AA odds ratio: 0.692, 95\% confidence interval (CI): 0.4-1.199, $p=0.188$; GG/AG odds ratio: $3.333,95 \% \mathrm{Cl}: 1.917-$ 5.795, $p=0.001$; AA/AG odds ratio: $0.208,95 \% \mathrm{Cl}$ : $0.124-0.348, p=0.342]$.

We conclude that $A / A$ and then $G / G$ in our patients were associated with breast cancer risk but there is no relation between presence of $A / G$ and increase of breast cancer risk.

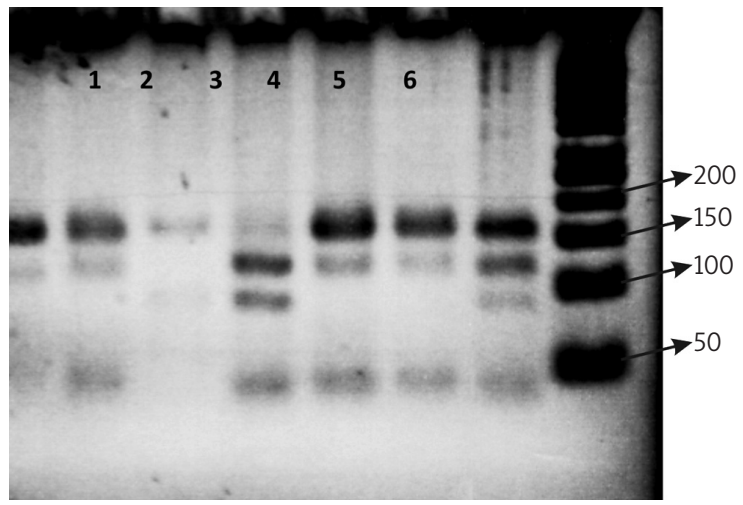

Figure 1. Polymorphism analysis of the ERCC1 intron 1. The PCR products were digested with restriction enzyme Mboll in groups 1, 4, 5 and 6; $A G$ genotype (167 bp, 114 bp, 83 bp, 49 bp, 6 bp), 3; AA genotype (114 bp, 83 bp, 49 bp, 6 bp) 2; GG genotype (167 bp, 83 bp, 6 bp); (ladder 50 bp) 


\section{Discussion}

Numerous studies address associations of polymorphisms in DNA repair genes and cancer risk [1] Accurate and efficient DNA repair is crucial for genomic integrity and fidelity.

The DNA repair system is complex, governed by more than 125 genes, many of which are polymorphic [7-9]. Two DNA repair genes, ERCC2 and ERCC1, whose products are important in nucleotide excision repair, lie on chromosome 19q13.3 [10].

ERCC1 (ASE-1) is positioned in an anti-sense orientation to and overlaps with the gene for ERCC1 and is possibly involved with the RNA polymerase I transcription complex. Recent studies show that base excision repair is required to repair DNA lesions induced at low N-nitrosodiethylamine concentrations [11].

To our knowledge, no studies have published the associations of ERCC1 rs3212981 polymorphisms and breast cancer risk.

There have been several studies of ERCC2 variants with other cancers, most notably with head and neck cancers, lung cancer, and skin cancer $[1,3,12-16]$ but none have reported about ERCC1 intron 1. So we examined ERCC1 intron 1 and the association with breast cancer risk.

However, Hansen did not find associations between the ERCC1 polymorphisms, the haplotype and risk of colorectal cancer but ERCC1 Asn118Asn has been associated with risk of breast cancer and lung cancer [17].

In another study, Zhou found that excision repair cross-complementing group 1 (ERCC1) is the lead enzyme in the nucleotide excision repair process, and low expression of ERCC1 mRNA levels has been associated with higher risk of cancer. On the other hand, ERCC1 8092C > A polymorphism may modify the associations between cigarette smoking and lung cancer risk [18].

On the other hand, in another study Yu et al. suggested that alteration at codon 118 within the ERCC1 gene may exist in platinum-sensitive and platinum-resistant ovarian cancer tissues [19].

In another study it was seen that the expression of ERCC1 was particularly lower in TNBCs than other types of breast cancers [20]. But in one study by Schöffski, there was seen a low BRCA1 and high ERCC1 in a population of sarcomas [21].

We previously reported a significant association of the ERCC2 polymorphism K751Q and R156R with breast cancer risk [22], but now, in this paper we have reported about the association between ERCC1 C8092A and breast cancer risk.

In this report, we examine ERCC1 polymorphism with breast cancer and controls. In this study we conclude that there is a relation between presence of T/T of ERCC1 genotype and increase of breast cancer risk.

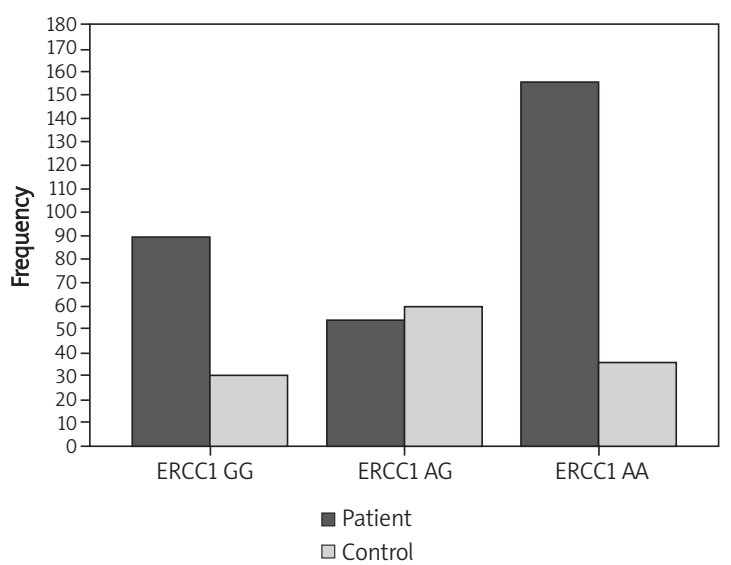

Figure 2. ERCC1 genotype frequencies $[n(\%)]$ for cases and controls: Analyses of 300 affected women and 126 controls for ERCC1 genotype frequency shows that $A A$ genotype has the highest frequency in the patient group and $A G$ genotype has a decrease in the patient group compared to the control group control and another group

\section{Acknowledgments}

We would like to thank all the patients for their kind collaboration in our projects, and the Islamic Azad University for supporting this Research.

Finally, we appreciate and thank the head and physicians of the Special Medical Centre, Tehran, Iran, who helped us during this project.

\section{References}

1. Goode EL, Ulrich CM, Potter JD. Polymorphisms in DNA repair genes and associations with cancer risk. Cancer Epidemiol Biomarkers Prev 2002; 11: 1513-30.

2. Mousavi SM, Montazeri A, Mohagheghi MA, et al. Breast cancer in Iran: an epidemiological review. Breast J 2007; 13: 383-91.

3. Zhu Y, Spitz MR, Amos Cl, Lin J, Schabath MB, Wu X. An evolutionary perspective on single-nucleotide polymorphism screening in molecular cancer epidemiology. Cancer Res 2004; 64: 2251-7.

4. Wrensch M, Kelsey KT, Liu M, et al. ERCC1 and ERCC2 polymorphisms and adult glioma. Neuro-Oncology 2005; 7: 495-507.

5. Vogel U, Hedayati M, Dybdahl M, Grossman L, Nexo BA. Polymorphisms of the DNA repair gene XPD: correlations with risk of basal cell carcinoma revisited. Carcinogenesis 2001; 22: 899-904.

6. Rieder MJ, Livingston RJ, Braun AC. Homo-sapiens excision repair cross-complementing deficiency, complementation group 1 (ERCC1) gene, and complete cds. (2002). NCBI (National Center for Bioinformatics). Accession \#AF512555. (NIEHS-SNPs, Environmental Genome Project, NIEHS ES15478, Department of Genome Sciences, Seattle, Wash.) Available at http://www.ncbi.nlm.nih.gov/entrez/viewer.fcgi?db= nucleotide \&val $=21105796$.

7. Ng PC, Henikoff S. Accounting for human polymorphisms predicted to affect protein function. Genome Res 2002; 12: 436-46. 
8. Ronen A, Glickman BW. Human DNA repair genes. Environ Mol Mutagen 2001; 37: 241-83.

9. Zhu Y, Spitz MR, Amos Cl, Lin J, Schabath MB, Wu X. An evolutionary perspective on single-nucleotide polymorphism screening in molecular cancer epidemiology. Cancer Res 2004; 64: 2251-7.

10. Smith JS, Tachibana I, Pohl U, Lee HK. A transcript map of the chromosome 19q-arm glioma tumor suppressor region. Genomics 2006; 4: 44-50

11. Aiub CA, Mazzei JL, Pinto LF, Felzenszwalb I. Participation of BER and NER pathways in the repair of DNA lesions induced at low N-nitrosodiethylamine concentrations. Toxicol Lett 2004; 154: 133-42.

12. Benhamou S, Sarasin A. ERCC2/XPD gene polymorphisms and cancer risk. Mutagenesis 2002; 17: 463-9.

13. Hou SM, Falt S, Angelini S, et al. The XPD variant alleles are associated with increased aromatic DNA adduct level and lung cancer risk. Carcinogenesis 2002; 23: 599-603.

14. Sturgis EM, Zheng R, Li L, et al. XPD/ERCC2 polymorphisms and risk of head and neck cancer: a case-control analysis. Carcinogenesis 2000; 21: 2219-23.

15. Zhou W, Liu G, Miller DP, et al. Gene-environment interaction for the ERCC2 polymorphisms and cumulative cigarette smoking exposure in lung cancer. Cancer Res 2002; 62: 1377-81.

16. Zhou W, Liu G, Miller DP, et al. Polymorphisms in the DNA repair genes XRCC1 and ERCC2, smoking, and lung cancer risk. Cancer Epidemiol Biomarkers Prev 2003; 12: 359-65.

17. Hansen RD, Sørensen M, Tjønneland A, Overvad K. A haplotype of polymorphisms in ASE-1, RAI and ERCC1 and the effects of tobacco smoking and alcohol consumption on risk of colorectal cancer: a Danish prospective case-cohort study. BMC Cancer 2008; 8: 54.

18. Zhou W, Liu G, Park S, Wang Z, Wain JC. Gene-smoking interaction associations for the ERCC1 polymorphisms in the risk of lung cancer. Cancer Epidemiol Biomarkers Prev 2005; 14: 491-6.

19. Yu JJ, Mu C, Lee KB, et al. A nucleotide polymorphism in ERCC1 in human ovarian cancer cell lines and tumor tissues. Mutat Res 1997; 382: 13-20.

20. Kim D, Jung W, Koo JS. The Expression of ERCC1, RRM1, and BRCA1 in Breast Cancer According to the Immunohistochemical Phenotypes. J Korean Med Sci 2011; 26: 352-9.

21. Schöffski P, Taron M, Jimeno J, Grosso F. Predictive impact of DNA repair functionality on clinical outcome of advanced sarcoma patients treated with trabectedin: a retrospective multicentric study. Eur J Cancer 2011; 47: 1006-12.

22. Hosseini M, Houshmand M, Ebrahimi A. the ERCC2 K751 polymorphism is associated with breast cancer risk. Arch Med Sci 2009; 35: 455-9. 